\title{
The Application of the Inquiry Teaching Method in Badminton Teaching in Colleges
}

\author{
Lei Xiaoming, Ling Liu(corresponding author *) \\ Physical Education Institute, Yuxi Normal University, Yuxi City, Yunnan \\ Province, 653100, China
}

\begin{abstract}
Inquiry teaching method can give full play to students' subjective role and encourages them to explore and research new knowledge. Besides, this model can cultivate their creative spirit and thinking, and enhance their creative ability and cooperative ability. Based on the author's learning and practical experience, this article analyzed the inquiry teaching method with the use of the experimental research, questionnaire survey and literature materials. Then, the paper discussed the application of the inquiry teaching in badminton teaching. The results show that the implementation of inquiry teaching model in badminton teaching can improve students' learning habit, stimulate their learning interest and learning initiative, and enhance the learning effect.
\end{abstract}

Keywords: Inquiry teaching; Badminton; Teaching experiment

\section{Introduction}

China is a powerful nation in badminton and badminton is a highly popular fitness project in China. In recent years, with the the college physical education teaching reform deepening, badminton is introduced into the sports classroom and becomes one of college students' favorite sport[1]. However, students have poor foundation on badminton. Besides, badminton requires skilled and exquisite techniques and it has high moving speed, various changes and intensive competition in contests. Therefore, it is difficulty for students to master and improve badminton skills, so that it is hard for teachers to achieve teaching 
objectives. In order to improve the teaching effect, the author tries to introduce inquiry teaching method into badminton teaching.

\section{Procedures of Inquiry Teaching Model in the Badminton Class}

\subsection{To raise questions}

First of all, according to the goal of badminton teaching, teachers can tell students the research field, guide them to think and raise exploratory questions. Then, teachers should list questions with different specific content, which are most likely to stimulate students' interest to participate in the research and which are worthy of exploring[2]. Moreover, teachers can create a good learning atmosphere and scene with the help of high-level videos and teachers' beautiful demonstration. For example, in badminton serve teaching, teachers can ask the following questions: how to play the ball that is difficult for the other side to respond? How to move your opponent around the court? How to make opponents' hand trembling when he or she catch the ball?

\subsection{To establish hypothesis}

Through teachers' guidance and students' positive thinking and discussion, we should propose a variety of possible solutions or ways to these questions. At that time, the hypothesis that students established is a solution and way to the question based on their own experience and knowledge. Sometimes the hypothesis is very different. Teachers should fully allow students with different levels to express their views freely and summarize students' hypotheses for further verification. We can take the returning ball speed as an example. The questions and hypotheses from students may include: What is a spike? Why do we make a spike? We can make a spike with the full arm waving to hit the ball; we can make a spike with the arm and wrist generating explosive power to hit the ball[3].

\subsection{To Explore, discuss and demonstrate the hypothesis}

In order to answer the above questions, teachers can provide necessary assistance and information. Students can verify the hypothesis independently, observe others, cooperate with each other or discuss with teachers directly. In addition, they can practice, analyze and judge the hypothesis with the help of the network and relevant books to draw a more reasonable conclusion. In this process, teachers should provide rapid, effective and necessary theoretical and practical help and guidance for students to experience and find answers. For example, for the above hypothesis, teachers can suggest students to think about the question from the badminton serve position, backswing and precipitation sequence of the body in order to guide students conduct in-depth inquiry learning. 


\subsection{To summarize and improve the hypothesis}

Teachers guide students to conduct further supplement and improvement based on the previous practice, experience, discussion and verification, so that students can make improvement of the hypothesis, experience and results to draw a scientific and reasonable conclusion[4]. After that, students can experience, verify and exchange this conclusion once again, so that they can make comprehensive progress in theoretical learning and practice. For example, in view of the previous hypothesis, tips and preliminary conclusion, teachers can summarize the hypothesis from the serve position, hard shot and following ball in accordance with the key elements of badminton serve techniques. Furthermore, they should discuss and answer students' questions and help them establish body proprioception to get the successful learning experience ultimately.

\section{An Application Experiment of Inquiry Teaching Method in Badminton Teaching in Colleges}

\subsection{The research objective}

The Teaching Program for National College Physical Education Course requires that colleges should give full play to the dominant role of students and the leading role of teachers. Besides, colleges should strive to promote open and inquiry teaching methods. Teaching methods should stress individuation and diversity and promote interaction between teachers and students. What's more, colleges should raise students' enthusiasm to participate in activities, give full play to their creativity and improve their ability of self-study and self-training. As the main content of school education, physical education should be closely around the innovative spirit and practical ability to reform and innovate the concept and methods continuously[5]. This paper conducted a contrast experiment and made an analysis of the inquiry teaching model in badminton teaching to seek for a new way to cultivate students' innovative consciousness and ability, which can provide reference for the further reform of the badminton teaching.

\subsection{Research subjects}

The research subjects are students who were enrolled in Yuxi Normal University in 2014 and 2015. The experimental group has 70 students and the control group has 70 students.

\subsection{Research methods}

The author referred to relevant information about badminton courses, inquiry teaching and teaching reform in the library or on sports journal websites. Then, the researcher gave out two sets of questionnaires with a total of 280 questionnairs to 4 classes which were selected randomly and recycled 280 
questionnaires. The effective recovery rate was $100 \%$. The author tested the influence of inquiry teaching model on the badminton teaching effect by the contrast experiment. Experimental class and control class adopted inquiry teaching model and the traditional teaching model for an academic year respectively.

0 people.

\section{Results and analysis}

\subsection{The comparison of learning outcomes}

Table 1 The comparison of the comprehensive evaluation of skills

\begin{tabular}{|c|c|c|}
\hline Rank & $\begin{array}{c}\text { Experimental } \\
\text { group (70 students) }\end{array}$ & $\begin{array}{c}\text { Control group (70 } \\
\text { students })\end{array}$ \\
\hline Excellent (90-100 grades) & $28 \%$ & $20 \%$ \\
\hline Good (80-89 grades) & $32 \%$ & $22 \%$ \\
\hline Medium (70-79 grades) & $24 \%$ & $34 \%$ \\
\hline Pass (60-69 grades) & $16 \%$ & $12 \%$ \\
\hline Failure (below 60 grades) & $0 \%$ & $12 \%$ \\
\hline
\end{tabular}

It can be observed from the above table: the excellent rate, good rate and failure rate of the experimental group are significantly better than those of the control group; the excellent rate of the experimental group is eight percent higher than that of the control group; good rate of the experimental group is higher than that of the control group by 10 percentage points; the excellent and good rate is significantly higher than that of the control group. The passing rate of the experimental group is $100 \%$, while the failure rate of the control group is $16 \%$. This fully shows that the use of inquiry teaching model is more conducive to students' learning and mastering of the basic technical skills that they have learned than the traditional teaching model[6]. The inquiry model has acceleration in the effect and improvement of college badminton teaching.

\subsection{The comparison of cognitive attitudes}

Table 2 The comparison of students' interest

\begin{tabular}{|c|c|c|}
\hline Rank & $\begin{array}{c}\text { Experimental } \\
\text { group (70 students) }\end{array}$ & $\begin{array}{c}\text { Control group (70 } \\
\text { students) }\end{array}$ \\
\hline Very interested in & $32 \%$ & $8 \%$ \\
\hline Interested in & $44 \%$ & $28 \%$ \\
\hline A little interested in & $19 \%$ & $40 \%$ \\
\hline Not interested in & $5 \%$ & $24 \%$ \\
\hline
\end{tabular}

The analysis results of the questionnaires show that $76 \%$ students in the experimental group are interested in the teaching model, while only $36 \%$ students in the control group are interested in the teaching model. Students' interest and acceptability of inquiry teaching model in the experimental group is stronger than that of the control group, which is conducive to stimulating students' initiative 
and enthusiasm for classroom exercises and changes students' passive acceptance of knowledge and boring simple imitation in the traditional teaching model. This model creates good conditions for students to play their dominant role in learning .

\subsection{The comparison of the learning process}

Table 3 The comparison of students' communication ways during the break

\begin{tabular}{|c|c|c|}
\hline Rank & $\begin{array}{c}\text { Experimental } \\
\text { group (70 } \\
\text { students) }\end{array}$ & $\begin{array}{c}\text { Control group (70 } \\
\text { students) }\end{array}$ \\
\hline Communicate with partners & $92 \%$ & $81 \%$ \\
\hline Communicate with teachers & $75 \%$ & $89 \%$ \\
\hline Communicate with other students & $80 \%$ & $32 \%$ \\
\hline Seldom communicate with others & $0 \%$ & $8 \%$ \\
\hline
\end{tabular}

According to the survey results of students' communication ways during the break, the proportion of the "communicate with partners" is the highest in the experimental group, while the proportion of the "communicate with teachers" in the control group is the highest, which indicates that some students in the experimental group have changed their way to exchange and receive information[7]. They do not entirely depend on the teachers' guidance and they like to communicate with peers or classmates to get information. In the control group, other communication ways assume a definite proportion, but the rate of information exchange with the teachers is $100 \%$. In other words, most students have absolute dependence on the teachers' information. In addition, there is a clear gap between the proportion of the "communication with other students" in the two groups. The proportion of this option in the experimental group is as high as $80 \%$ compared with $32 \%$ in the control group. It can be observed that in the traditional teaching model, students' information exchange is highly passive. Most students communicate with teaches and major partners and they lack exchanges with other students. From the proportion in the experimental group and teachers' observation in the course, we can find that students' learning initiative and enthusiasm with the guidance of the inquiry teaching model is much stronger.

\section{Conclusion}

The inquiry teaching model can promote the improvement of the basic technical skills and the academic achievement of the badminton students as the traditional teaching model. Besides, the inquiry teaching model is more conducive to stimulating students' interest and initiative in learning. However, when teachers apply inquiry teaching, they should pay attention to the design of teaching procedures and the direction of teaching guidance. Moreover, they should integrate the inquiry teaching with the traditional teaching model well, so that the 
two teaching models can learn from each other and give play to each other's complementary advantages.

\section{References}

[1] Ren Haibo. A Research of the Application of the Game Teaching Method in College Badminton Teaching. Contemporary Sports Technology, (25), pp.20-21, 2016.

[2] Lu Yunlong. An Analysis of the Application of Inquiry Teaching Method in the Badminton Teaching in Colleges. Sport, (14), pp.73-74, 2015.

[3] Su Ping. A Discussion on the Application of Inquiry Teaching Method in Badminton Class. Journal of Guangzhou Sport University, (04), pp.97-98, 2003.

[4] Wang Xing. A Discussion and Thinking on College Badminton Teaching Methods. Journal of Changzhi College, (02), pp.122-124, 2012.

[5] Han Chunlong. An Analysis of the Application of Inquiry Teaching Method in Badminton Teaching. Heilongjiang Science and Technology Information, (28), pp.200-201, 2011.

[6] Xu Hengyong. An Experimental Research on the Inquiry Teaching Model in Badminton Teaching. Sports World (Academic Edition), (02), 92-93, 2008.

[7] Duan Wenyi, He Haining, Wan Qilin and Gao Feng. An Experimental Research on the Inquiry Teaching Method in Badminton Serve Teaching. Liaoning Sports Science and Technology, (03), 70-71, 2004. 